\title{
A utilização do palhaço no ambiente hospitalar
}

\author{
ANDRÉ FURTADO DE AYALLA RODRIGUES \\ WELLINGTON JORGE NUNES FILHO
}

Acadêmico de Medicina do 12을 Período da Universidade de Pernambuco, participante do projeto de extensão universitária Palhaçoterapia e formado em técnicas de clown há 5 anos.

Acadêmico de Medicina do $7^{\circ}$ Período da Universidade de Pernambuco, participante do projeto de extensão universitária Palhaçoterapia e formado em técnicas de clown há 3 anos. 


\section{- RESUMO}

O palhaço se faz presente na maior parte das culturas da humanidade exercendo os mais diversos papéis; desde participantes de rituais sagrados à conselheiros reais. Atualmente, 0 palhaço é visto como um ser transgressor de normas e capaz de satirizar as fragilidades humanas deixando-as mais leves. Foi exatamente essa ressignificação que garantiu o sucesso do palhaço dentro do ambiente hospitalar. Em 1986, pela primeira vez o palhaço usou seu dom dentro de um hospital satirizando as rotinas típicas desse ambiente. As consequências da atuação puderam ser observadas ainda durante o espetáculo quando crianças previamente deprimidas participavam ativamente das atividades propostas. Desde então, houve uma rápida progressão na quantidade de grupos - constituídos por voluntários ou artistas - que levam esse tipo de linguagem para dentro do hospital como forma de apoio às crianças internadas, familiares e profissionais de saúde. Apesar da resistência por parte de alguns profissionais de saúde, estudos recentes demonstram a eficácia desse tipo de ação dentro do hospital.

\section{- PALAVRAS-CHAVE}

Palhaço, hospital, ambiente hospitalar.

\section{- ABSTRACT}

The clown has been part of most of human culture, playing diverse roles, from participant in sacred rituals to royal counselor. Currently, the clown is seen as a transgressor and capable of satirizing the human frailties. It was this reframing that ensured the success of the clown inside the hospital environment. In 1986, for the first time a clown used his ability inside a hospital satirizing the typical routines of that environment. Those actions resulted in consequences that could be observed during the show, when previously depressed children participated actively in the activities proposed. Since then, there has been a rapid progression on the amount of groups - made up of volunteers or artists - which take this kind of language into the hospital as a form of support to the hospitalized children, their family and, also, health professionals. Despite resistance by some health professionals, recent studies have demonstrated the effectiveness of this kind of initiative.

\section{- KEYWORDS}

Clown, hospital, hospital zone.

\section{Introdução}

É comum, ao término do curso Médico, os formandos realizarem o juramento de Hipócrates, considerado o pai da Medicina. Dele, a princípio, extraem-se apenas certos preceitos que guiarão os médicos em sua futura carreira. Sob um olhar mais atento percebe-se que Hipócrates, ao descrever seu exercício como médico, cita a palavra "profissão" 3 vezes e de modo semelhante utiliza a palavra "arte" as mesmas 3 vezes. Esse é apenas um exemplo para lembrar como a Medicina - aqui utilizada como sinônimo de algo mais amplo, a Saúde - não deve ser relegada ao simples papel de lidar com doenças.

Baseando-se no juramento, no qual a Medicina é considerada Arte, deve-se lembrar novamente dos antigos gregos. Além de médicos, todos foram filósofos. Médicos e Filósofos. Segundo o Michaelis, filosofia significa "Estudo geral sobre a natureza de todas as coisas e suas relações entre si; os valores, o sentido, os fatos e princípios gerais da existência, bem como a conduta e destino do homem". Portanto, 
nota-se que esses homens enxergam o indivíduo inserido dentro de um contexto, nunca isolado do ambiente que o cerca. Analisando o espaço no qual o homem se insere, um dos principais aspectos que o influenciam é a Cultura.

Cultura, porém, é algo subjetivo. Em 1952, Kroeber e Kluckhohn, pesquisando sobre o assunto, chegaram a 162 definições para o termo. Considerando Cultura como os usos e costumes de uma sociedade nas diversas estratificações sociais e que, segundo Christian Parentino, representa uma transmissão seletiva de conceitos de uma geração para outra, como ela se relaciona com a Saúde?

Ser profissional da área da Saúde é muito mais que descobrir e tratar doenças ou ter um conhecimento técnico-científico apurado. É a arte de entender a pessoa que está procurando sua ajuda. Partindo desse pressuposto, não podemos nos desvincular da cultura, já que ela é a mola mestre para que nós entendamos uns aos outros. Mas como estudá-la fará do profissional da saúde mais capacitado a exercer sua função? Adquirindo e ampliando nossa Cultura, podemos prover um atendimento de melhor qualidade a qualquer paciente já que passaremos a ter uma visão diferenciada do mesmo, tratando-o de maneira personalizada e individual com melhor entendimento sobre suas angústias e anseios.

Faz-se necessário dizer que a Saúde está passando por um momento crítico. Não existe mais a figura do médico que era quase o amigo da família e ia fazer a consulta de casa em casa. O que existe hoje é uma miríade de especialidades, um médico cardiologista, uma fisioterapeuta respiratória ou uma enfermeira do pronto-socorro, treinados apenas para ser resolutivos com a doença e esquecer o indivíduo. Para isso utilizam métodos como a Ressonância Magnética ou Endoscopia, entre outros que quando usados em excesso, podem trazer mais malefícios que benefícios. Tais procedimentos afastam o profissional da saúde do âmago de sua profissão: o contato com o paciente.

Assim, na atualidade, existe quase um consenso sobre a necessidade de se "re-humanizar" a Saúde, de se desenvolver e fornecer recursos humanísticos para o processo de formação e de atuação do médico e dos diversos profissionais de saúde em geral. Uma iniciativa que vem ganhando adesão crescente de participantes nas escolas de Saúde brasileiras é a constituição de grupos de estudantes e profissionais que desenvolvem experiências artísticas, buscando estabelecer um diálogo com seus pacientes utilizando a linguagem não-verbal, a meta-linguagem e sua interpretação. Por meio da linguagem gestual (os gestos, o toque, o olhar, o sorriso), as afinidades simbólicas transmitem amor, cuidado, confiança, segurança e possibilitam a superação da solidão, tornando-se um elemento terapêutico, por meio do qual cada sujeito se revela ao outro.

Dentro das diversas formas artísticas de expressar e desenvolver essa capacidade nos futuros profissionais da Saúde, o Palhaço parece cumprir de maneira satisfatória o florescer de um olhar mais sensível e atento, centrado não apenas na doença, mas no paciente e em tudo que o circunda.

O objetivo desse artigo é fazer uma passagem histórica sobre a importância da figura do palhaço nas diversas sociedades, até os dias atuais e como eles podem se inserir na realidade da Saúde brasileira. 


\section{O palhaço e sua chegada aos hospitais}

A figura do palhaço está presente em todas as culturas da humanidade. Sua mais antiga expressão é a que se faz presente nos rituais sagrados em que ela é utilizada como elemento para espantar o medo, especialmente o da morte. Nos momentos mais dramáticos, o riso surge como uma válvula de escape nas tensões do grupo, numa tentativa de retorno à normalidade. Em inúmeras épocas, encontramos a prática de rituais em que se imitam coxos, cegos e leprosos, provocando o riso nos participantes.

Durante a Idade Média, em alguns países da Europa, surgiu a figura do bobo da corte para entreter os senhores feudais. Vestido com um chapéu de várias pontas e guizos em cada extremidade, tal qual uma coroa disforme e de cabeça para baixo, o bobo da corte também trazia em suas mãos um bastão de madeira com uma cabeça de bobo esculpida, que servia para ele dialogar, ou uma bexiga de porco com sementes em seu interior, tal qual um chocalho, utilizado para imitar o cetro real, já que ele tinha que se vestir como uma paródia do rei. Além de fazer palhaçadas para alegrar as pessoas, os bufões tinham um espírito rebelde e anárquico, com a coragem para dizer coisas que outras pessoas temiam, pois poderiam ser presas ou condenadas à morte. Assim, os bufões se tornaram também conselheiros reais.

Os personagens do teatro grego, bem como da commedia dell'arte italiana, usavam máscaras cujos detalhes representavam alguma das características da sociedade da época. Um dos personagens mais populares é o Arlequim, que usa roupa com losangos coloridos e máscara negra. Como um palhaço, aparentemente tolo, sempre acaba se saindo bem devido a sua astúcia. Os atores se escondiam atrás das máscaras e representavam de acordo com o personagem. Já o palhaço, ao utilizar-se da menor máscara do mundo, o nariz vermelho, ao invés de se esconder, acaba se revelando, expondo o seu ridículo e provocando o riso a partir dele, uma vez que "A palavra ridículo vem do latim ridiculus, que significa ser risível. Quer dizer, ridículo é alguém de quem os outros têm vontade de dar risadas".

Um aspecto interessante de se realçar é a origem do nome palhaço. A palavra paIhaço vem do italiano paglia, que significa palha. Isso porque a maioria das roupas dos palhaços era feita do mesmo tecido listrado que se faziam os colchões. Para proteger o corpo dos tombos, a roupa dos palhaços era afofada em determinadas partes, fazendo-os se parecer com colchões. Como os colchões tinham palha em seu interior, quem ficava dentro daquela roupa esquisita era chamado de palhaço. Dá-se também o nome de clown, grotesco, truão, bobo, excêntrico, Tony e augusto a esta figura louca, capaz de provocar gargalhadas ao primeiro olhar, que é o palhaço. Já clown, que significa palhaço em inglês, vem da palavra clod que significa torrão de terra, estúpido, rústico, ou seja, ligado ao camponês e ao meio rústico em que ele vive, a terra.

Segundo Luís Otávio Burnier,

[...] na verdade palhaço e clown são termos distintos para se designar a mesma coisa. Existem, sim, diferenças quanto às linhas de trabalho. Como, por exemplo, os palhaços (ou clowns) americanos, que dão mais valor à gag, ao número, à ideia; para eles, o que o clown vai fazer tem um maior peso. Por outro lado, existem aqueles que se preocupam principalmente com o como o palhaço vai realizar seu número, não importando tanto o que ele vai fazer; assim, são mais valorizadas a lógica individual do clown e sua personalidade; esse modo de trabalhar é uma tendência 
a um trabalho mais pessoal. Podemos dizer que os clowns europeus seguem mais essa linha. Também existem as diferenças que aparecem em decorrência do tipo de espaço em que o palhaço trabalha: o circo, o teatro, a rua, o cinema, etc. (BURNIER, s/d).

Com o passar dos tempos a figura do palhaço, ou mesmo do clown, adaptouse a inúmeras modalidades até chegar ao inusitado espaço hospitalar, na promoção da Saúde. Em 1986, por exemplo, Michael Christensen, diretor do Big Apple Circus, de Nova lorque, foi convidado a participar das comemorações do dia do coração no Columbia Presbyterian Babies Hospital,quando optou por fazer uma satirização às rotinas médicas e hospitalares, utilizando o teatro clown. Primeiramente, ele se apresentou para as crianças que puderam se deslocar até o ambiente do espetáculo no qual ele utilizou a linguagem do clown. Ao perceber que o espetáculo foi bem aceito, Michael teve a oportunidade de se apresentar para as crianças em seus leitos. $O$ resultado surpreendeu a todos, pois as crianças que se demonstravam deprimidas e apáticas participaram ativamente das atividades propostas.

Após outras visitas, o Hospital decidiu investir na continuidade do trabalho, nascendo então a Clown Care Unit. Em 1988, Wellington Nogueira, ator brasileiro que, na ocasião, morava em Nova lorque, passou a integrar a trupe do Clown Care Unit, e ao retornar ao Brasil, em 1991, criou um programa semelhante, iniciando seus trabalhos no Hospital e Maternidade Nossa Senhora de Lourdes, em São Paulo. O projeto brasileiro, batizado com o nome "Doutores da Alegria", tinha como objetivo utilizar a arte do teatro clown para avaliar a necessidade das crianças hospitalizadas e colocar ao seu dispor truques, magia e malabarismo; com isso devolveria à criança um pouco do controle sobre o corpo e sobre sua vida, algo que lhe é totalmente tirado quando se encontra enferma e hospitalizada e, ainda, favoreceria uma atitude mais positiva e ativa em relação à enfermidade e sua recuperação.

O trabalho dos "Doutores da Alegria" acabou por influenciar diversas iniciativas no Brasil e, desde então, inúmeros grupos iniciaram trabalhos semelhantes em hospitais em todo o território nacional, dentre eles,está o projeto de extensão universitária da Universidade de Pernambuco: Palhaçoterapia-UPE.

Nessa perspectiva de trabalho, o palhaço se dirige ao que é saudável numa criança que está doente, no intuito de manter vivas as suas possibilidades de criar, de sonhar, de rir. De fato, o mundo do palhaço é bem diferente daquele do hospital, mas seu universo está muito próximo ao da criança. Essa proximidade cria rapidamente uma grande cumplicidade entre os dois. A aproximação, num segundo plano, com os médicos e enfermeiros e mesmo os acompanhantes, se dá através da própria criança. A estrutura hospitalar, desde a sua organização espacial setorizada, com suas áreas ambulatoriais, de internação e de tratamento intensivo, até a hierarquização da equipe de Saúde, passando pelo acesso seletivo ao medicamento, está associada à descoberta do corpo humano como objeto de investigação científica. Assim, o palhaço quando traz no seu corpo, e na sua ação, o indício de uma temporalidade e de um lugar diferentes daqueles nos quais ele se encontra, abre um mundo novo no ambiente hospitalar: propõe outra lógica, redimensiona lugares, desestabiliza relações estruturadas de poder, estimula a comunicação e chama a atenção para a ligação entre corpo e indivíduo, entre a forma e o conteúdo, entre o exterior e o interior, porque movimenta imaginação e crença numa perspectiva física, concreta. 
Dessa forma, como conclui Ana Lucia Martins Soares, em seu artigo intitulado Palhaço de Hospital: Proposta metodológica de formação:

[...] Sua pesquisa sobre a capacitação para atuação em hospitais acabou por certificar o palhaço de hospital como uma modalidade de cômico, emparelhada com a dos palhaços de circo, de feiras, de teatro, bufões, bobos, tolos, os arlequins da commedia dell'arte (SOARES, s/d.).

\section{Justificativa do trabalho na saúde}

Mesmo com tantos anos de trabalhos prestados à Saúde, não é raro ler críticas ao trabalho exercido dentro do hospital, aos estudantes e profissionais que utilizam o palhaço como método adjuvante à promoção da Saúde.

Como diz um velho ditado, "rir é o melhor remédio". Até a década de 1950, ele poderia ser simplesmente uma suposição baseada em experiências do dia-a-dia. Porém, Olds e Milner, trabalhando pela respeitada Universidade McGill, no Canadá, demonstraram, a possível existência de centros relacionados ao prazer, os quais estariam localizados em nosso cérebro. Esses centros não foram bem aceitos pela comunidade científica da época, pois nunca se conseguiu provar que tais centros eram realmente relacionados ao prazer (KRINGELBACH, PHIL, BERRIDGE, 2010). Isso não quer dizer, porém, que a busca dos cientistas pelo baú do prazer foi descartada. Recentemente, foi comprovado por vários grupos independentes de pesquisadores, através de exames de imagem do cérebro, que piadas verbais e não-verbais, além de programas de TV, todas essas modalidades mostravam que algumas partes específicas ficavam mais estimuladas, como lobo temporal posterior e o giro frontal inferior esquerdo (BEKINSCHTEIN et al., 2011). Atualmente, as pesquisas continuam a ser realizadas e, pelos conceitos atuais, não se comenta acerca de pontos isolados de prazer, porém de redes hedônicas cerebrais que podem ser disparadas pelos mais diversos estímulos, por exemplo, relações interpessoais - um dos fatores mais importantes para a felicidade (KRINGELBACH; PHIL; BERRIDGE, 2010). Além de tudo isso, Kringelbach, Phil e Berridge citam Charles Darwin, criador da teoria evolucionista, ao relembrar que ele acreditava nas reações afetivas como funções importantes dentro da evolução das espécies, pois elas seriam respostas adaptativas ao meio ambiente.

Além disso, os efeitos dos processos de hospitalização sobre o desenvolvimento infantil são muito discutidos. Pode-se destacar que, além das mudanças na rotina e nos hábitos de sono, higiene e alimentação, a criança é submetida a situações sobre as quais não tem muita escolha. Os autores mencionam, também, a ausência de espaço lúdico no hospital, que seria bastante terapêutico neste caso. Argumentam, também, que a arquitetura hospitalar, com enfermarias coletivas com pouca luz, predomínio da cor branca nas paredes e nas roupas dos profissionais, presença de equipamentos muitas vezes estranhos, como bombas de infusão e monitores barulhentos, procedimentos agressivos e dolorosos e ainda a utilização de uma linguagem técnica, causam profundo estranhamento nas crianças, nos adolescentes e seus acompanhantes (CASTRO NETO, 2000; MIRTE, 2000; LIMA, 1996). Dessa maneira, a utilização da linguagem do clown seria uma forma a contornar esses problemas advindos da hospitalização. 


\section{Hospitais e palhaços}

A utilização de palhaços em hospitais não segue uma regra, um lugar-comum. Alguns falam nela como uma terapia, outros como uma estratégia para determinados objetivo, além do terapêutico. Algumas terminologias são utilizadas, como a do médico-clown ou do clown-terapeuta. Ainda, pode-se falar das pessoas que apenas utilizam a linguagem do palhaço para praticar o voluntariado, sem nenhum conhecimento teórico prévio.

Como disse Hunter "Patch" Adams (2002 sobre a utilização dos palhaços no ambiente hospitalar.

[...] É inerente a essas preocupações que o clowning precisa ser um contexto, não uma terapia. É engraçado para esse clown dizer "palhaçoterapia". Claro que é terapêutico! Se a estratégia do amo existisse em nossa sociedade, ninguém precisaria da palhaçoterapia. Mas, nossos hospitais modernos e práticas médicas ao redor do mundo, todos gritam para o reconectar dessa prestação de cuidados com compaixão, alegria, amor e humor. [...] Se permitirmos que a estratégia do amor permaneça apenas como uma terapia, estamos dando a entender que há momentos nos quais ela não é necessária. Mas, se nós nos comprometermos a cultivar o amor como contexto, nós seremos continuamente chamados a criar uma atmosfera de alegria, amor e riso (ADAMS, 2002, p. 447-448).

Dessa maneira, pode-se notar que o maior expoente do Palhaço em Hospitais defende a utilização do clown como uma estratégia para um plano maior: a difusão de um ambiente hospitalar mais acessível e amoroso, até ao ponto em que ela estaria intrínseca à prática da Saúde com a perpetuação de um ambiente mais humanizado, de acordo com o que se espera dos médicos, enfermeiras ou técnicos em enfermagem de um hospital. Ele ainda diz que nunca exigiu de seus voluntários a experiência em clown. Apenas a vontade de levar amor e humor ao próximo.

Deve-se lembrar que não são todos que pensam como Patch Adams. Por exemplo, no Canadá, os clown de hospitais - sejam eles médicos-clown ou clown-terapeuta - se reuniram e formaram a The Canadian Association of Therapeutic Clowns / L'Association Canadienne des Clowns Therapeutique - em tradução livre, Associação Canadense de Clowns-Terapeutas - que é regida por um rígido Código de Ética com declaração de princípios e regulamento (KOLLER, GRYSKI, 2007) Em pesquisa realizada pelos "Doutores da Alegria" com organizações ao redor do mundo que trabalham com palhaço no hospital, demonstrou-se que a maior parte dos programas remuneram seus participantes, mas, ao mesmo tempo, exigem deles pré-requisitos para a participação, como, curso específico de palhaço, experiência prévia em circo, autodidatismo, entre outros.

Independente de como se pense a atuação do palhaço dentro do hospital, é evidente a rápida progressão da presença destes no ambiente da Saúde. Por exemplo, o Therapeutic Clown Program realizado no Hospital for Sick Children, no Canadá, atende uma média de 20.000 crianças anualmente. Ainda na pesquisa realizada pelos "Doutores da Alegria", a maior parte das organizações realiza, ao menos, 1001 visitas/leito no período de um ano. 
O trabalho realizado pelos clowns nos leitos e enfermarias de um hospital tem vários significados. Para exemplificar isso, Avner, o Excêntrico, coloca de maneira sucinta como deve se portar um palhaço: "O palhaço cria um mundo no espaço vazio, ao invés de entrar num mundo que já existe" (EISENBERG, 2005)

Desse pressuposto para a prática hospitalar, retiram-se pontos que, ao serem analisados, conseguem demonstrar a eficácia do trabalho para os participantes desse jogo: o paciente, a equipe de saúde e os familiares. Conforme Koller e Gryski, o objetivo do clown-terapeuta é minimizar o stress para o paciente e seus familiares durante hospitalização e tratamento. Segundo Linge (2013), o objetivo de um encontro-clown não é sempre ser divertido, mas para que a criança e todo seu "registro emocional" possam ser notados e reconhecidos, com os efeitos que advém disso. Ainda de acordo com Linge, esse encontro com o clown no espaço hospitalar também faz bem aos irmãos que não estão doentes, pois, na maioria das vezes, ficam em segundo plano em relação ao irmão internado e encontram dificuldades em expressar seus desejos ou de se fazer ser ouvido.

O benefício do médico-clown também é pode ser observado no estudo realizado em 2005 por Vagnoli e Caprilli, que aferiram o efeito da presença de clowns na ansiedade pré-operatória. Seus resultados mostraram que, apesar da resistência por parte médica, a intervenção clownesca é eficiente em reduzir a ansiedade, tanto da criança, como da família, nos momentos do pré-operatório.

Essa intervenção pode acontecer das mais variadas maneiras, mesmo porque ainda não há uniformidade quanto à metodologia que deva ser utilizada. Porém, pode-se notar que, ainda que não haja critérios específicos, a maior parte dos relatos sobre atuações clownescas no setor hospitalar converge em alguns pontos, como a aceitação do paciente, parente ou profissional da saúde, antes de qualquer tipo de interação ou a atuação em duplas de palhaço. Um questionamento importante é em relação à quantidade de vezes na semana nos quais deveria haver presença dos palhaços nos setores de saúde. Esse número pode variar de 01 vez na semana até mais de 04 vezes por semana. Ainda não se identificou qual é a melhor estratégia, mas Linge (2013) cita Hansen, Kibaek, Martinussen, Kragh e Hejl quando diz que quanto mais frequente, os encontros com os clowns se tornam mais significativos para o próximo.

Ainda: segundo o Dr. John M. Driscoll Jr (apud KOLLER; GRYSKI, 2007): “Quando uma criança começa a sorrir, isso significa que, provavelmente, ela esta começando a se sentir melhor".

Mas, será que todas as crianças e parentes, acham importante o papel do palhaço no hospital? Linge (2013) expressa em sua meta-análise que apenas um pequeno número de pacientes tinham algum tipo de restrição quanto à presença do clown. Ele ainda cita Platt, Ruch (2009) e Titze (2009) que argumentam sobre a possibilidade de catagelofobia - de ser ou estar ridículo - e como isso poderia ser uma variedade da ansiedade relacionada à timidez.

Deve-se ressaltar que a maior parte dos pacientes, profissionais da Saúde e parentes acredita ser salutar a presença de palhaços no hospital. Mesmo que o papel do palhaço não fique claro dentro do contexto hospitalar, ora o palhaço é visto como alguém que esta ali para apenas trazer alegria e um momento de distração, ora como parte efetiva do corpo de profissionais, não parece haver qualquer dúvida de que o clown deve fazer parte do dia-a-dia. Koller e Gryski mostraram que os staffs médicos, 
em sua grande maioria, não tinham qualquer tipo de preocupação quanto ao trabaIho realizado pelos clowns-médicos.

\section{Conclusão}

Através dessa revisão, mostramos como o palhaço, desde suas origens e significados, podem estar inseridos dentro de um contexto hospitalar e seus benefícios ao próximo. Com a atual necessidade de "re-humanizar" o ambiente hospitalar, o clown ganhou seu espaço naturalmente por ser uma figura que transgride regras. É exatamente essa transgressão que desconstrói, juntamente com o paciente/parente/ profissional de saúde, o hospital e transforma-o em um ambiente menos sombrio e amedrontador. Além disso, apesar dos estudos sobre o tema serem relativamente escassos, as evidências são suficientemente sólidas para justificar o investimento de grupos de palhaços em hospitais. Portanto, com a rápida expansão da utilização dessa linguagem, faz-se necessário haver mais pesquisas e estudos sobre o tema, assim como um melhor mapeamento dos grupos que trabalham com o palhaço para que esforços possam ser somados, assim como há no Canadá.

\section{Referências}

ADAMS, Patch. Humour and love: the origination of clown therapy. Postgraduate Medical Journal. 2002; v.72 n.922, p 447-8. Disponível em: <http://pmj.bmj.com/content/78/922/447.full>

BEKINSCHTEIN et al. Why clowns taste funny: The relationship between humor and semantic ambiguity. The Journal of Neuroscience, v. 31, n. 26, p. 9665-9671, jun. 2011. Disponível em: < htpp://www.jneurosci.org/content/31/26/9665.full> Acesso em: 25 jan. 2013.

BRIANI, MC. O ensino médico no Brasil está mudando? Revista Brasileira de Educação Médica, v. 25, n. 3, p. 73-77. 2001.

BURNIER, Luís Otávio. O clown. Disponível em: <http://www.grupotempo.com.br/tex_burnier.html\#1a> . Acesso em: 6 fev. 2013.

CERIBELLI, Carina et al . A mediação de leitura como recurso de comunicação com crianças hospitalizadas. Revista Latino-Americana de Enfermagem, Ribeirão Preto, v. 17, n. 1, feb. 2009. Disponível em: <http://www.scielo.br/scielo.php?script=sci_arttext\&pid=S0104-11692009000100013\&lng=en\&nrm=iso>. Acesso em: 14 fev. 2013.

DOUTORES DA ALEGRIA. Palhaços em hospitais - Brasil/Mundo. Disponível em: < http://www.doutoresdaalegria.org.br/download/Pesqlnt_port.pdf Acesso em: 28 jan. 2013.

EISEMBERG, Avner. Os princípios do palhaço. Disponível em: <http://www.avnertheeccentric.com/eccentric_principles_portuguese.php> Acesso em: 14 fev. 2013.

FRANÇANI GM; ZILIOLI D; SILVA PRF; SANTANA RPM; LIMA RAG. Prescrição do dia: infusão de alegria. Utilizando a arte como um instrumento na assistência à criança hospitalizada. Revista Latino-Americana de Enfermagem, Ribeirão Preto, v. 6, n. 5, p. 27-33. 1998. 
KOLLER,D; GRYSKI,C. The life threatened child and the life enhancing clown: towards a model of therapeutic clowning. Evid Based Complement Alternative Medicine, v. 5, n. 1, p. 17-25, mar. 2008. Disponível em: <http://www.ncbi.nlm.nih.gov/pmc/articles/PMC2249744/> Acesso em: 25 jan. 2013.

KRINGELBACH,ML; PHIL,D; BERRIDGE, KC. The Functional Neuroanatomy of Pleasure and Happiness Morten L. Kringelbach, D.Phil. Discovery Medicine, v. 9, n. 49, p. 579-587, jun. 2010. Disponível em: < http://www.ncbi.nlm.nih.gov/pmc/articles/PMC3008353/> Acesso em: 28 jan. 2013.

LIMA, RAG et al . A arte do teatro Clown no cuidado às crianças hospitalizadas. Revista da Escola de Enfermagem, São Paulo, USP, v. 43, n. 1, mar. 2009.

LINGE, L. Joyful and serious intentions in the work of hospital clowns: A meta-analysis based on a 7-year research project conducted in three parts. International J. Qualitative Stud Health Well-being, v. 8. 2013. Disponível em: <http://dx.doi.org/10.3402/qhw.v8i0.18907> Acesso em: 28 jan. 2013.

MITRE, RMA; GOMES R. A promoção do brincar no contexto da hospitalização infantil enquanto ação de saúde. Ciência Saúde Coletiva, v. 9, n. 1, p. 147-54. 2004.

SOARES, ALM. Palhaço de Hospital: Proposta metodológica de formação. Disponível em: < http://www. portalabrace.org/vcongresso/textos/pedagogia/Ana\%20Achcar\%20-\%20Palhaco\%20de\%20Hospital\%20 Proposta\%20Metodologica\%20de\%20Formacao.pdf > Acesso em: 25 jan. 2013.

THEBAS, C. O livro do palhaço. São Paulo: Companhia das Letrinhas, 2005. (Coleção profissões).

VAGNOLI et al. Clown Doctors as a Treatment for Preoperative Anxiety in Children: A Randomized, Prospective Study. Pediatrics, 116; e563. 2005. Disponível em: <http://pediatrics.aappublications.org/content/116/4/e563.full.html> Acesso em: 28 jan. 2013. 